Research, part of a Special Feature on Resilience Through Multi-scalar Collaboration

\title{
A Critical Systems Approach to Social Learning: Building Adaptive Capacity in Social, Ecological, Epistemological (SEE) Systems
}

\author{
Daniel D. P. McCarthy ${ }^{1}$, Debbe D. Crandall ${ }^{2}$, Graham S. Whitelaw ${ }^{3}$ Zachariah General $^{4}$, and \\ Leonard J.S. Tsuji ${ }^{4}$
}

\begin{abstract}
This paper presents a conceptual tool, or heuristic, for describing the epistemological context for social learning within complex social-ecological systems. The heuristic integrates several definitions of social learning that emphasize the importance of critical reflection and its collaborative nature and that it is rooted in and oriented toward practice through social interactions. The conceptual tool is useful in identifying and conceptually mapping different perspectives based on types of learning described along three dimensions: typology of knowledge; different levels of critical reflection; and scale. The heuristic was originally developed in the context of an environmental planning process in southern Ontario, Canada, and is applied to identifying barriers and bridges to social learning in the case of flood damage reduction in a remote First Nations community in northern Ontario, Canada.
\end{abstract}

Key Words: adaptive capacity; critical systems thinking; First Nations; social learning

\section{INTRODUCTION}

Social change is needed if society is going to adequately address the environmental challenges threatening human societies and the global ecosystems on which they rely. We need a new approach to environmental management that supports collective action and reflection directed towards improving the management of human and environmental interrelations. We refer to this as the social learning approach. Keen et al. (2005:1).

Keen et al. (2005: 4) suggest that "social learning is the collective action and reflection that occurs among different individuals and groups as they work to improve the management of human and environmental interrelations. Webler et al. (1995) provide an overview of the origins of the concept of social learning, and document the tension within the literature between psychological and sociological views. The psychological or pedagogical perspective on social learning, as represented by Bandura $(1971,1986,1991)$ is based on the work of social-psychologist Kurt Lewin and revolves around the individual process being dependent on social interactions. In contrast, the sociological perspective moves beyond individuals learning in a social context to learning within social structures, such as organizations or institutions (e.g., Argyris 1993) or viewing social learning as an expression of coordinated cognitive and normative adjustments resulting in social change (e.g., Wynne 1992).

Mezirow (1998) emphasizes the importance of critical reflection in learning, and especially, transformative learning. Keen et al. (2005) and Wals (2007), for example, highlight the importance of critical reflection in social learning. Keen et al. (2005: 9) regard critical reflection as one of the "five braided strands of social learning," and note that, "social learning is a process of iterative reflection that occurs when we share our experiences, ideas and environments with others." Keen et al. (2005) further describe the process of social learning as cyclical, moving from diagnosing, to designing, to doing, to developing, which helps to evolve the definition of the problem, and the cycle begins again.

\footnotetext{
${ }^{1}$ Waterloo Institute for Social innovation and Resilience (WISIR) University of Waterloo, ${ }^{2}$ Save the Oak Ridges Moraine Coalition, ${ }^{3}$ Queen's University, ${ }^{4}$ University of Waterloo
} 
Pahl-Wostl et al. (2008) define social learning in the context of linked social-ecological systems as involving the development of "relational capacities, both between social agents, in the form of learning how to collaborate and understand others' roles and capacities differently, and also between socialecological systems (sustainability learning)" (PahlWostl et al. 2008: 1). Thus, social learning is inherently collaborative. Reed et al. (2010) define social learning as a change in understanding that goes beyond the individual to become situated within wider social units or communities of practice through social interactions between actors within social networks. This latter definition emphasizes the scaling-up of learning from the individual and that social learning is rooted in practice, taking place through social interactions.

Our work builds on research that has applied complex systems thinking to building resilience and fostering adaptive capacity within complex socialecological systems (Gunderson et al. 1995, Berkes and Folke 1998, Kay et al. 1999, Gunderson and Holling 2002, Berkes and Folke 2003, WaltnerToews et al. 2004, Walker and Salt 2006). The development of adaptive capacity is critical to resilience in social-ecological systems (Armitage 2005) where adaptive capacity refers to the aspect of resilience that reflects learning, flexibility to experiment and adopt novel solutions, and development of a generalized response to broad classes of challenges (Walker et al. 2002: 3). Two of the key dimensions of adaptive capacity are learning with uncertainty and combining different types of knowledge for learning (Armitage 2005). This work also integrates research that explores critical and reflective approaches to systems thinking (Jackson 2000, Midgely 2000). Work on critical systems thinking emphasizes the strong links between philosophy, methodology, and intervention. As a result, we propose the explicit incorporation of knowledge generation and learning into a concept of social-ecological systems or social-ecological-epistemological (SEE) systems.

The definitions of social learning presented above do not explicitly express the need to integrate different types of knowledge (Armitage 2005) through practice and social interactions (Reed et al. 2010) and the need to reflect critically on one's underlying philosophical assumptions in order to scale-up knowledge generation to reflect social learning. Therefore, we define social learning as an on-going, adaptive process of knowledge creation that is scaled-up from individuals though social interactions fostered by critical reflection and the synthesis of a variety of knowledge types that result in changes to social structures (e.g., organizational mandates, policies, social norms). The resulting conceptual model of social learning can be used to describe the epistemological context for environmental planning and governance.

In the tradition of Glaser and Strauss' (1967) grounded theory, we began with broad, generative questions but did not allow any theoretical or conceptual framework to limit our critical systemsbased approach (Midgley 2000, Trochim 2005). This conceptual model of social learning was developed in the context of the case study of the Oak Ridges Moraine collaborative planning process in southern Ontario, Canada to enable researchers and practitioners involved in the case to conceptually map different perspectives of stakeholders throughout the process (McCarthy 2009). This paper examines the application of the model to the case study of the Fort Albany First Nation on the west coast of James Bay in northern Ontario, Canada, and the community's response to a recent flood event. The institutional and policy contexts of the two case studies are significantly different: the southern Ontario case is a rapidly urbanizing region with a well-developed governance and policy regime, whereas the northern, First Nations case is a remote, undeveloped area, that is experiencing increasing resource development pressure within a nascent, formal policy context. The differences between the two cases provide an opportunity to explore the utility of the conceptual model. This exploratory research differs from descriptive research (in-depth, case study description for inductive or simply descriptive purposes), correlational research (establishing relationships or connections between two or more variables) or explanatory research (establishing causal links through standardized protocols; Robson 1993). Robson (1993) characterizes exploratory research as inquiry that assesses phenomena through a new perspective or conceptual lens. Although it is unlikely that it will ever be capable of identifying causal relationships, through further application, such as this work, the heuristic can move beyond exploratory to descriptive and possibly, through extensive further testing, correlational research. Implications based on the research and conclusions are presented for consideration in other environmental planning and governance contexts. 


\section{SOCIAL, ECOLOGICAL, EPISTEMOLOGICAL (SEE) SYSTEMS CONCEPTUAL MODEL OF SOCIAL LEARNING}

The Social-Ecological-Epistemological (SEE) systems model of social learning, introduced above, developed through a critical systems thinking approach (Jackson 2000, Midgley 2000), integrates insights from Flyvbjerg's (2001) typology of knowledge, Flood and Romm's (1996) triple-loop learning and Giddens' (1984) structuration theory (Fig. 1). It describes the requirements of social learning along three axes or dimensions: typology of knowledge; critical reflection; and scale of social-ecological structures. The integration of these three dimensions provides the opportunity to map a trajectory of social learning in a particular social-ecological system context and to map various knowledge perspectives. The conceptual basis for these axes or dimensions of social learning is described below.

First, the typology of knowledge axis is intended to describe how learning occurs in dynamic tension among three types of knowledge, "episteme," "techne," and "phronesis," originally articulated by Aristotle and then interpreted by Flyvbjerg (2001) to provide a new rationale for social science. "Episteme" is based on general analytical rationality and is intended to be universal, invariable, and context independent (Flyvbjerg 2001) and is reinterpreted in this work as scientific ("episteme"), local ("techne"), and governance ("phronesis"). Modern equivalents of the original Aristotelian term include "epistemology" and "epistemic." "Techne" is based on instrumental rationality and is pragmatic, variable, and context dependent (Flyvbjerg 2001). The original concept appears today in terms such as "technique," "technical,"and "technology." Finally, the third Aristotelian type of knowledge "phronesis," interestingly, has no contemporary equivalent. "Phronesis" is based on ethical, practical value rationality. It is pragmatic, variable, and context dependent and involves deliberation about values with reference to practical application of theory (praxis; Flyvberg, 2001). Flyvberg (2001) argued that instead of social science attempting to develop "episteme" as the natural sciences do, it is more appropriate for the social sciences to attempt to develop "phronetic" knowledge.

We have reinterpreted Flyvberg's (2001) use of these Aristotelian intellectual principles within the context of social learning in complex socialecological systems and related them to critical reflection and cross-scalar dynamics (discussed below). To enhance accessibility to a larger audience, the terms scientific, local, and governance were used in place of, and equivalent to, Flyvberg's "episteme," "techne," and "phronesis," respectively. These terms were used by Oak Ridges Moraine interviewees (described below) to describe knowledge requirements for environmental policy change in that context and resonated strongly with Flyvberg's definitions (above). Specifically, scientific knowledge ("episteme") is defined as universal, invariable, and context independent knowledge generated through standard, western scientific methods and so, in a policy context, carries great rhetorical weight. Examples include knowledge of ecological, hydrological, and sociological systems. Local knowledge ("techne") is pragmatic, variable, and context dependent and is generated through local experience and historical community interactions. Examples can include Aboriginal traditional knowledge, knowledge of local cultural heritage, and local human interactions. And governance knowledge ("phronesis") is pragmatic, variable, and context dependent and involves deliberation about values that reflect an understanding and informed interpretation of political, legal, and regulatory discourses or regimes in a given context. Examples can include interpretations of national, provincial/state, and local laws, regulations, and policies for a specific issue.

The second axis, critical reflection, describes three different levels or "loops" of learning. Flood and Romm (1996: xi) describe three centers of learning associated with the three loops that represent very different questions. The first center or loop of learning asks "Are we doing things right?" The second center or loop questions the goals or assumptions of the first loop by asking "Are we doing the right things?" The third center or loop, which represents the innovative contribution to the organizational or social learning literature, asks if "power structures are acting too much in support of definitions of "rightness" or conversely if any presumed 'right way' is becoming too forceful? "This triple-loop view of social or organizational learning explicitly integrates notions of power and sets learning in a social or political context.

The third axis describes how learning crosses scales. Learning, especially social learning, requires an understanding of cross-scalar interactions and 
Fig. 1. SEE systems conceptual model of social learning.

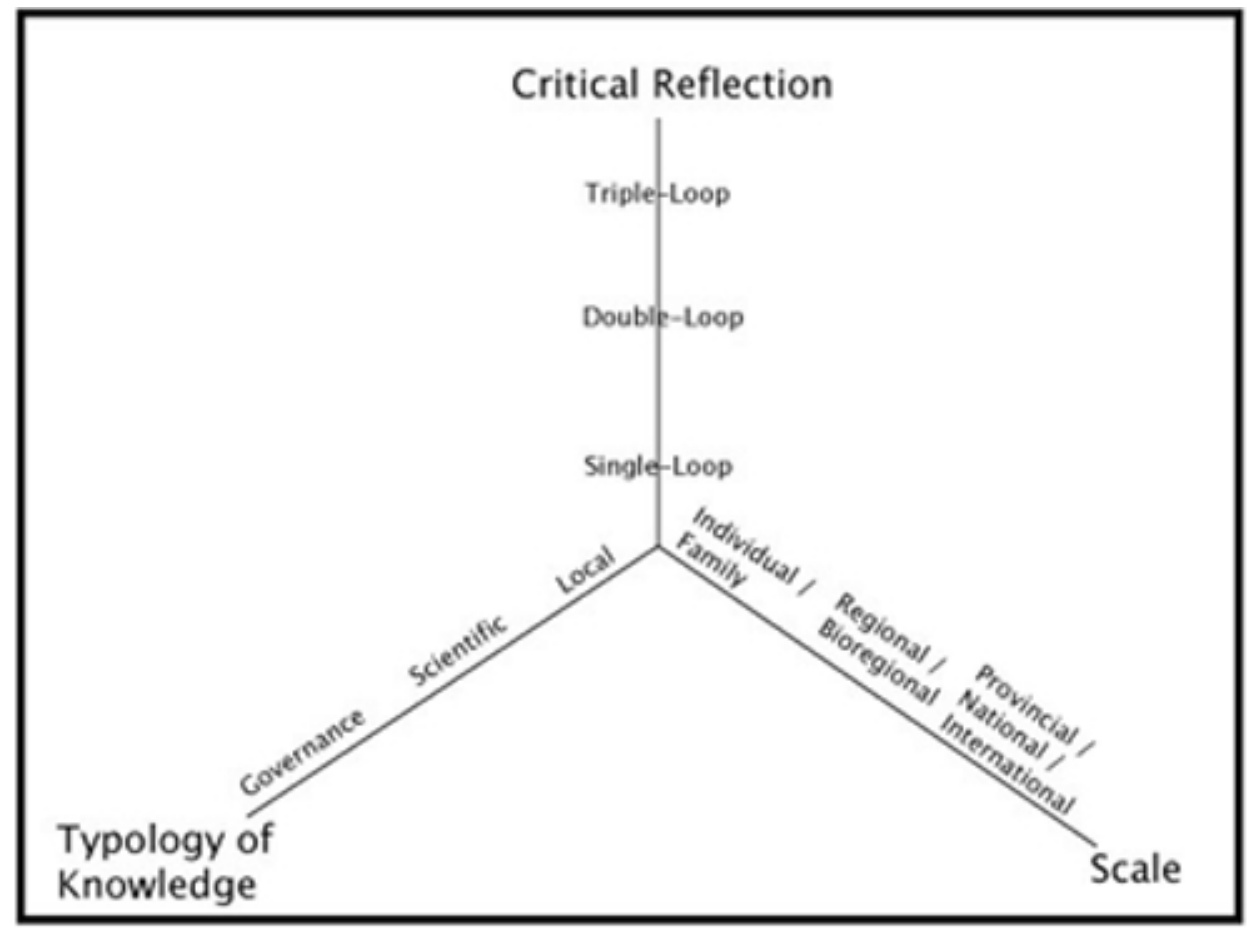

emergence. Based on insights from the work of Giddens (1984) structuration theory, the third axis highlights the dialectic relationship between individuals and the creation of social structures through repeated behaviors and rule systems. According to Giddens (1984), social structures such as rules, laws, regimes, and institutions emerge out of an individual agent's behavior and an individual agent's behavior is constrained by the rules and structures that emerge over time. Therefore, it is useful to view complex social-ecological systems as creative constructions used by agents to understand and intervene in such systems. The development of this understanding provides insights into the evolution and practical use of theories (praxis) that result in the evolution management regimes and rules that bound or constrain individual agents' behaviors (Giddens 1984, Gunderson et al. 1995, Gunderson and Holling 2002). Thus, it is useful to view the relationship between individual agents and their understanding of complex social-ecological systems as dialectic, that is, you cannot talk about a system without describing the knowledge system that led to its creation.
The SEE Systems Conceptual Model of Social Learning was originally developed in the context of research on the Oak Ridges Moraine collaborative planning process (1980-2005; McCarthy 2009). By the mid- to late-1980s, development in the Greater Toronto Area (GTA) had expanded north and begun to threaten the existence of a large glacial landform, the Oak Ridges Moraine (ORM), that served an important hydrological function and was a prominent green space corridor. In 2001, the Ontario provincial government passed the Oak Ridges Moraine Conservation Act (ORMCA) and approved the Oak Ridges Moraine Conservation Plan (ORMCP) that protected $92 \%$ of the ORM from new urban development. The passing of this legislation is attributed, in part, to more than a decade of lobbying pressure from a number of nongovernmental organizations (NGOs), including the Save the Oak Ridges Moraine (STORM) Coalition. Knowledge sharing and learning on a large, social scale was evident in the enactment of the ORMCA and ORMCP (Whitelaw 2005, Whitelaw and McCarthy 2008, McCarthy 2009).

Three illustrations from the case of the Oak Ridges Moraine demonstrate the utility of this model. These 
examples are not meant to be an exhaustive list of the possible perspectives that could be described, rather they demonstrate the links between the empirical data and the emerging conceptual model.

The darkest region, in the center of Fig. 2, represents an individual or group whose perspective can be characterized by NIMBYism (Not In My Backyard). Individuals or groups concerned primarily with the immediate implications of development on their property value or privacy do not explicitly reflect on the broader impacts of development or even question the need for development. This perspective is quite often based on local knowledge and is generally focused on a very local scale of influence (i.e., one's property or tax structure of a local municipality).

The middle region on the figure represents the use of an ecosystem approach to planning based on conservation biology and landscape ecology principles and the concept of ecological integrity as a normative conservation goal embedded in the Oak Ridges Moraine Conservation Act (Government of Ontario 2001) and Plan (Government of Ontario 2002). This perspective is one in which an individual or group has critically reflected upon core assumptions. Interviewees described shifting from a NIMBY reaction to a broader understanding of the ecological and hydrological implications of moraine development. In this case, the need for strong scientific knowledge as a basis for preservation supplements local knowledge, whereas the scale of influence expands beyond individual properties to the entire moraine bioregion, including the surrounding watersheds and aquifers.

The outer region on the diagram is that of an integrated, sustainability viewpoint. Only a few respondents described moving beyond an understanding of the need for a change in normative goals to a critical reflection on the ethics of decision making and the power relations that reinforce certain normative policy goals. This example of triple-loop learning can be linked to, or can be the result of, an understanding of the overall governance system (i.e., the role of power in complex policy issues). The recent interest among some Oak Ridges Moraine stakeholders, especially those in the environmental movement, in the UNESCO World Biosphere Reserve designation, demonstrates a connection between the local and the international network of biosphere reserves. This interest also indicates an understanding of the shift in power relations on the moraine since the enactment of the ORMCA and ORMCP. With $92 \%$ of the Moraine protected from new development, many in the environmental movement are seeking collaborative initiatives with government and private-sector interests to build on conservation successes and move toward a sustainable landscape and healthy communities.

The three axes in the diagram are set in dynamic tension. That is, they are not completely independent from one another. Moving along one axis can result in a shift along one or both of the other axes. Yet, movement down any of the three axes does not necessarily imply or force movement down another. For instance, several members of Concerned Citizens of King Township-a longstanding STORM Coalition member-group-have demonstrated the use of all three types of knowledge and some measure of each level of critical reflection (single, double, and triple-loop learning) but explicitly maintain their focus at the scale of King Township. Their governance knowledge and reflection on power structures is centered within the boundaries of the township.

The intent of the mapping is to highlight different perspectives in a given context and how these can be reconciled for action through a process of social learning. It is critical to note that any mapping of perspectives on this model is meant to illustrate different, non-equivalent perspectives. Mario Giampietro (2003: 5) highlights the impossibility of obtaining the "right" picture of a given situation when dealing with complex systems. Giampietro (2003: 4) also notes that the possibility of multiple non-equivalent perceptions of the same situation is one of the typical characteristics of complexity and that "different perceptions of a given problem tend to reflect differences in the social context."

The SEE conceptual model of social learning can be used to understand the epistemological perspectives of individuals and organizations (agents) or institutions (structures) within an environmental policy and governance context. This paper argues that an integrated SEE systems framework, such as the one presented in Fig. 1 above, provides a social learning approach to environmental planning, policy making, and governance that fosters adaptive capacity and system resilience. 
Fig. 2. SEE systems conceptual model of social learning applied to the Oak Ridges Moraine case.

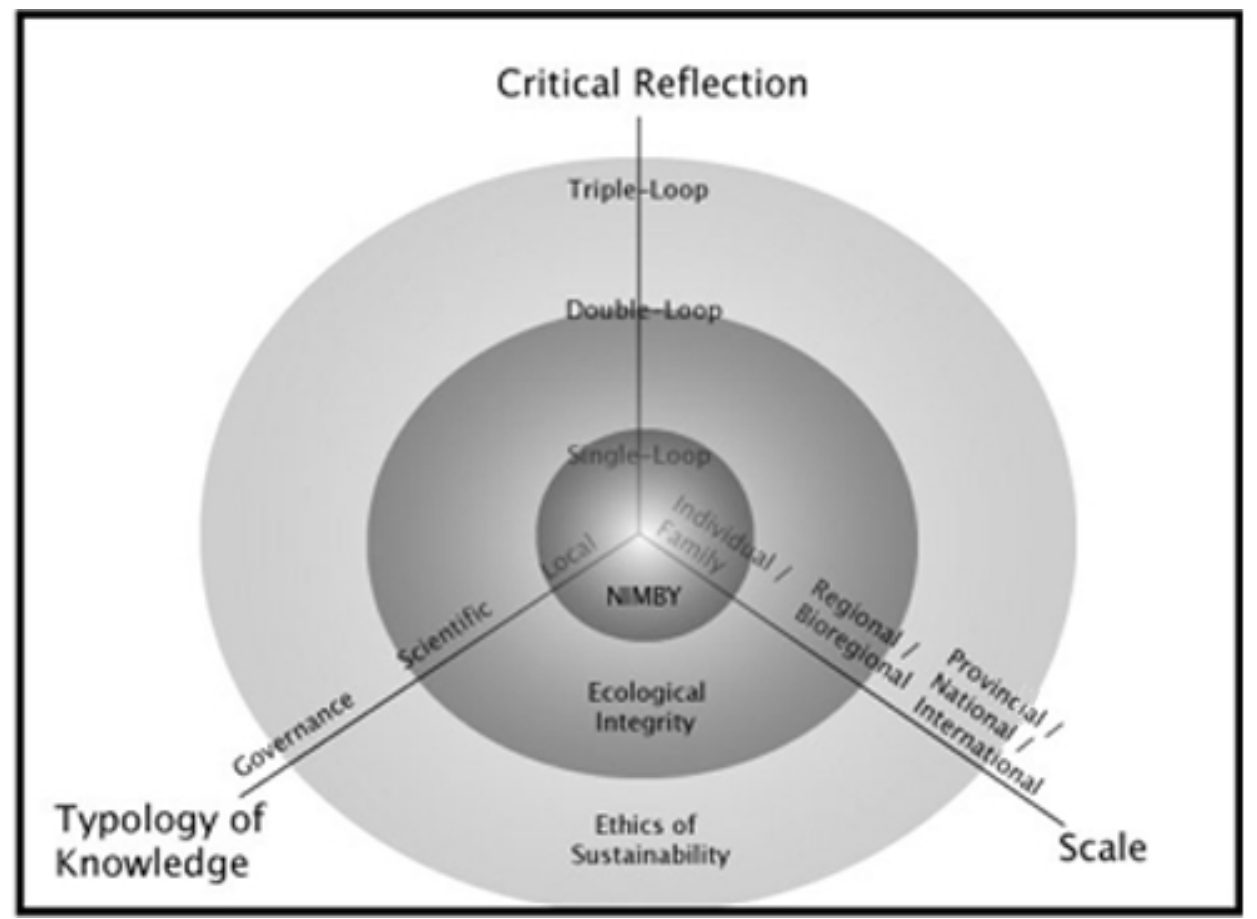

\section{METHODS}

\section{Primary Data Collection}

Qualitative data for the Fort Albany case were collected from 25 May 252008 to 4 June 2008, approximately 1 month after the 25 April 2008 ice jam on the Albany River that resulted in the flooding of Fort Albany. The data were collected using a culturally appropriate, semi-structured interview format that incorporated open-ended questions (Huntington 1998). In total, 51 interviews were conducted, including the Chief and four members of the Fort Albany Council, two band council staff members, eight community health staff members, three education staff members, two flood committee members, one water treatment plant employee and 33 Fort Albany community members, chosen at random.

Interview transcripts were analyzed using QSR NVivo, computer-assisted qualitative data analysis software. The use of qualitative data analysis software allowed us to systematize analytical procedures (Miles and Huberman 1994) for searching, storing, and managing qualitative data
(Gibbs 2002). NVivo was used to identify main themes and ideas within the interview transcripts and to help make connections between themes (Miles and Huberman 1994). Data from the Fort Albany case were used to apply and further the development of the conceptual model.

\section{Secondary Data Collection}

In context of the interviews, key respondents (e.g., the flood coordinator, the Chief, and members of the Council) were asked to identify the key documents for understanding the issues and events associated with the Fort Albany flood. In the followup e-mails, a request was made to these respondents for documents that they had offered to acquire on our behalf. Documents included relevant legislation, plans, policies, and regulations (e.g., Fort Albany Flood Watch) as well as media accounts (e.g., Canadian Broadcasting Corporation [CBC] coverage of the Fort Albany Flood).

Once all the documents were acquired, they were systematically reviewed as a means of triangulation and to enrich the SEE systems descriptions. 
O'Donoghue and Punch (2003: 78) define triangulation as a method of cross-checking data from multiple sources to search for regularities in the research data. Each document was reviewed for its purpose, content, and significance to the research. The document analysis was used to verify details regarding key events, key individuals, groups, organizations, agencies, etc., the role of knowledge and learning, and resulting shifts in policy identified in the context of the interviewees' responses to the Fort Albany flood.

\section{SOCIAL LEARNING IN THE FORT ALBANY FIRST NATION CASE STUDY}

The SEE systems conceptual model of social learning was developed as a descriptive heuristic to understand the evolution in stakeholder thinking that led to policy change on the Oak Ridges Moraine (McCarthy 2009). The utility of the model for describing the epistemological context of social learning can be explored in other case studies, such as the 25 April flood in the remote community of Fort Albany, and can form the basis for further research.

\section{Background}

The Mushkegowuk Territory is populated by approximately 10,000 First Nation Cree who inhabit remote coastal communities, including Moosonee, Moose Factory, Fort Albany, Kashechewan, and Attawapiskat (Tsuji and Nieboer 1999; see Fig. 3). These communities are represented at a regional level by the Muskegowuk Council. The community of Fort Albany First Nation has a population of approximately 850 . Their traditional lands are extensive and overlap with the traditional lands of the other First Nation communities in the area (Chief A. Solomon, Fort Albany First Nation, personal communication, 2008).

On 25 April 2008, the annual spring break-up occurred on the Albany River on the west coast of James Bay in northern Ontario. An ice jam resulted in the flooding of Fort Albany and an elevated flood risk to the community of Kashechewan, both remote First Nations communities located in the flood plain of the Albany River. Beginning on 25 April and continuing to 28 April, both communities were evacuated. Further north along the James Bay coast, a similar elevated flood risk due to the spring break- up on the Attawapiskat River resulted in the evacuation of the First Nation community of Attawapiskat. As many as 2,000 Cree from Fort Albany and Kashechewan were evacuated, and cost estimates for the evacuation are in the tens of millions of dollars (CBC 2008a). The 2006 evacuation of Kashechewan cost approximately \$20.2 million (Harries 2008). Millions of dollars have also been spent on dikes in both communities, and a 2005 report set repair costs for the existing dikes at \$30 million (Harries 2008).

Historically, the Mushkegowuk Crees' nomadic ancestors would have avoided floods by spending most of the year on higher ground on the Canadian Shield, hundreds of kilometers inland from James Bay, only venturing down the Albany River, closer to the Bay, in the summer (Lytwyn 2002). After the establishment of the Hudson Bay Company trading posts along the coast of James Bay, more and more of the nomadic Mushegowuk Cree began to live in the flood plain year round. Since the signing of Treaty 9 in 1905-1906 and the creation of the Fort Albany First Nation reserve and up to 2005, there have been at least four major floods in Fort Albany or Kashechwan (1966, 1972, 1976, 1985) according to Fort Albany flood records (Fort Albany First Nation Flood Watch 2006); in addition, there has been the 2006 flood in Kashechwan and the 2008 flood in Fort Albany. Various approaches to flood damage reduction have been employed from structural (such as dikes) to non-structural (such as the flood management committee).

Following a major flood in 1985, the Fort Albany First Nation commissioned the Fort Albany Flood Control Study in 1987. The purpose of this study was to "describe the history of flooding in the community, the causes of flooding, the likely recurrence of interval flooding, the consequences of the flood hazard and propose some remedial works to combat flooding" (Latham Group Inc. 1989: 1). The resulting recommendations were structural approaches to flood damage reduction in the form of a perimeter dike system and spillway control dikes (Latham Group Inc. 1989: 6-1).

At the request of the Chief and Council of Fort Albany First Nation, our research team sought to determine the reaction of community members to the flood and the evacuation. In speaking with members of the Fort Albany First Nation, it was clear that living with the annual risk of flood was just part of living in this remote community. Of 
Fig. 3. Map of the Muskegowuk Territory, west coast of James Bay, Ontario, Canada.

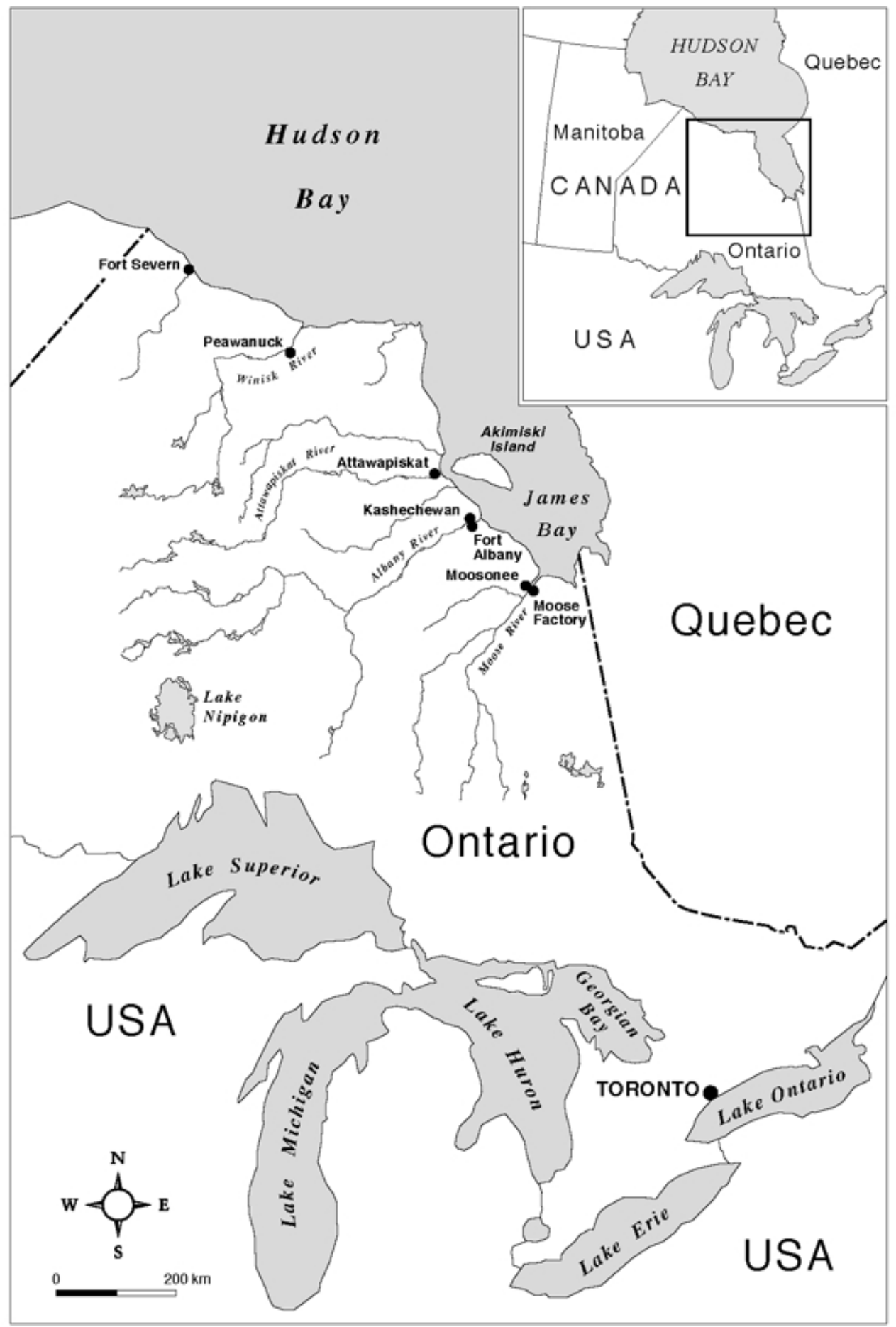


specific interest to this work, several different perspectives could be described or mapped on to the SEE systems conceptual model of social learning.

\section{Applying the SEE Model: Social Learning and Fostering Adaptive Capacity for Flood Damage Reduction for the Fort Albany First Nation}

The SEE conceptual model for social learning can be used to describe several perspectives in the context of flood damage reduction in the Fort Albany First Nation case. These descriptions might then be useful for identifying barriers to social learning and avenues for fostering adaptive capacity. The sample perspectives described below are not meant to be a comprehensive list of either the possible perspectives that could be described by this conceptual model or the perspectives represented in the community. Rather, they demonstrate the utility of the conceptual model for describing the relationship between different perspectives on an issue, the knowledge requirements for fostering social learning, and potential barriers to fostering adaptive capacity.

Although we did note discrepancies associated with sex, one perspective that was clearly articulated in the interviews, especially with males, was one of apathy. When asked about the flood, five interviewees made no comment, and six respondents indicated that they did not know the cause of the flood. When asked about their reaction to the evacuation, eight interviewees commented that the evacuation was a positive experience and had treated it as a vacation. This perspective is local in scale, with respondents referring only to the implications of the flood to themselves or their immediate family. These respondents did not question the assumptions that underlay the evacuation and, therefore, can be mapped to the single-loop of critical reflection (see darkest area on Fig. 4).

A second perspective revealed a broader understanding of the interconnections between land use, culture, language, and flood, indicative of First Nations traditional knowledge. Indicative of this is the fact that 22 of the 51 respondents indicated that the flood was nothing out of the ordinary. Eight respondents stated that they would have preferred to remain in the community, and three interviewees stated that the flood was exaggerated and that evacuation was an over-reaction by the federal and provincial government agencies. The only reason these respondents left was because the water treatment plant was to be shut down as the plant manager was participating in the evacuation. Eight interview respondents (mostly elders) indicated that, within recent memory, many community members would be out on higher ground, hunting on their traditional lands during spring break-up. These interviewees indicated that, although they may have returned to homes that needed repairing or sheds that needed to be relocated, at least this approach effectively removed the risk of injury or death as a result of flooding. These respondents (mostly elders) also noted that this approach to flood avoidance ensured that families were together, out on the land, engaging in traditional pursuits.

The current flood response committee structure, as instituted by provincial and federal authorities, provides funding for a flood coordinator and an elder advisor to be hired only a few weeks before spring break-up. In interviews, Chief and Council and flood coordination staff indicated that these timelines were insufficient to respond properly to a flood or to manage proactively for flood damage reduction. The current flood response approach combines a structural approach (i.e., dikes) with a limited, community-based flood coordination staff (i.e., temporally limited flood response committee).

Interviewees from the Fort Albany First Nation community question the wisdom of spending millions of dollars on existing approaches to flood damage reduction. Many of them argue for a more integrated and collaborative approach to flood damage reduction and emergency measures planning that would not only ensure the safety of the community members but also help preserve their Cree culture, language, and way of life. These insights are based on generations of Mushkegowuk Cree adapting to the regular flood conditions on the Albany River.

Building on this perspective, three key members of the community, a former chief, a councilor, and the deputy suggested a slightly different solution. Eight interviewees indicated that the money spent on the evacuation should instead have been spent in the community. In fact, it was suggested by three interviewees that instead of spending the millions of dollars on evacuations, the money should have been spent on an expansion of the recently built school, which also functions as an evacuation center. The existing school, built in 2001, was designed as an evacuation staging center. As such, it was constructed on higher ground (the 100-year 
Fig. 4. SEE systems conceptual model of social learning applied to the Fort Albany flood case.

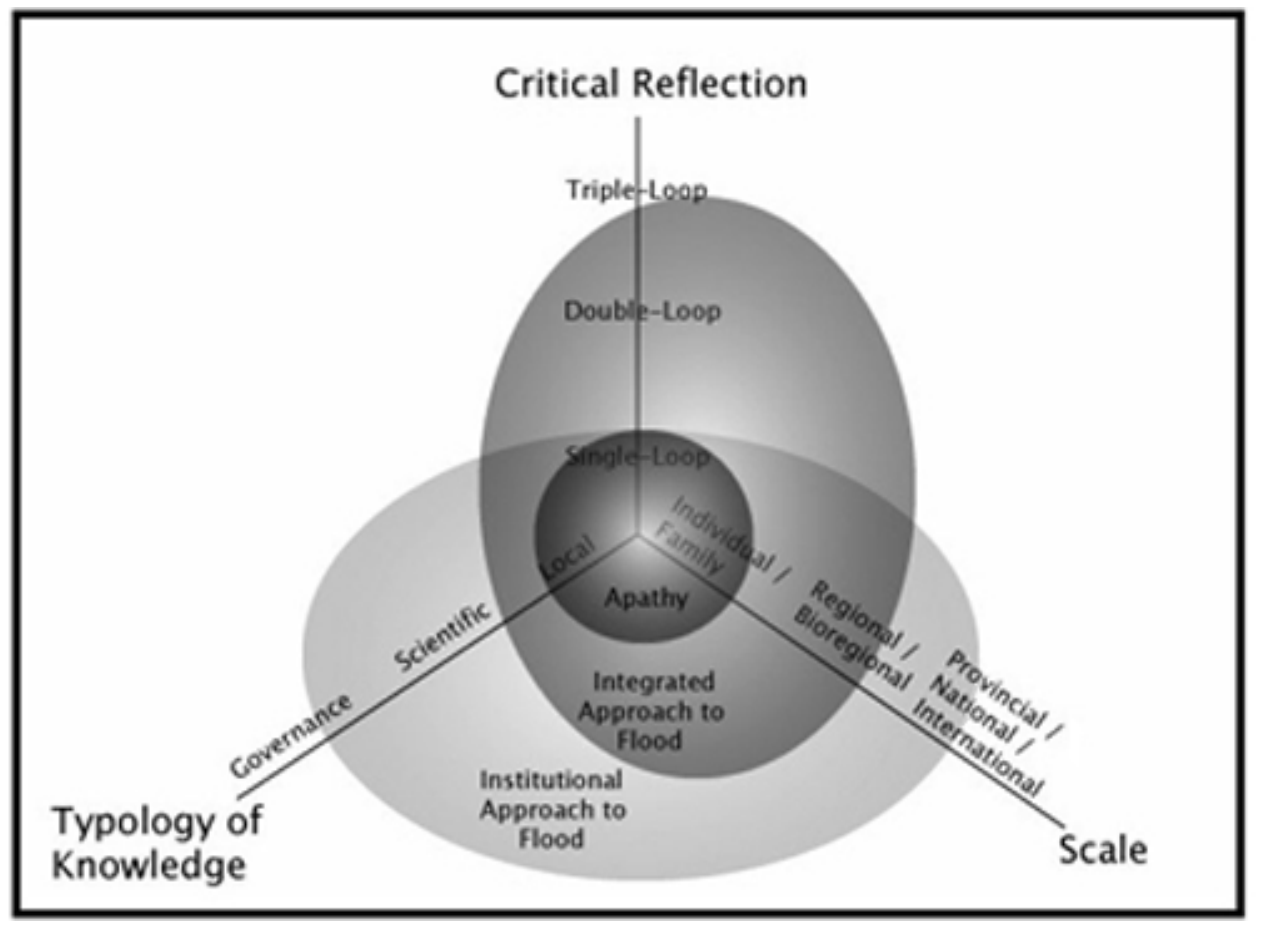

flood plain), with large common areas and a full commercial kitchen. The expansion proposed by interviewees would include a multi-use, hotel-style evacuation center that could be used in case of future floods and other emergencies, as well as for a conference center for local economic development and, perhaps most importantly, as a "shabotawon" or learning lodge. The shabotawon, in generations past, was a place where children would go to meet with elders, learn about their culture, language, and traditional pursuits including hunting, trapping, and tanning. They would then go out on the land with the elders to continue their learning. This perspective takes the seemingly discrete issue of the flood and integrates it with land use, local economic development, and the preservation of Cree culture and language.

This integrated, holistic view of flood damage reduction is based mainly on local, traditional knowledge that is context dependent. The authors recognize the complex and extensive discourse on the relationship between traditional ecological knowledge (TEK) and western science. It can easily be argued that TEK such as this can be seen to share common ground with western science (for example, Tsuji and Ho 2002). However, TEK should not require legitimization by proponents of western science, resilience, or adaptive capacity (e.g., Nadasdy 2007). However, such discourse is well beyond the scope of this work and, as such, we argue that the knowledge of the Albany River held by the Mushkegowuk Cree of the Fort Albany First Nation over multiple generations is context dependent and so will be mapped as local knowledge. The relevant scale of the perspective is that of the community and its traditional lands, relatively small in the provincial or national context. In terms of critical reflection, these respondents question the wisdom of recent approaches to flood damage reduction and criticize the imbalance of power between community members and provincial and federal decision makers and, therefore, represents doubleloop learning (see medium-colored area on Fig. 4).

The third perspective that could be mapped (mainly derived from secondary sources and community perspectives on federal and provincial flood damage reduction policies and regulations) is that of the agencies and groups charged with dealing with 
flood risk. This group includes representatives from the Canadian federal government, the Ontario provincial government, Mushkegowuk Council, and members of the Fort Albany community. It was this group that ultimately decided to evacuate the community of Fort Albany as well as Kashechewan and Moose Factory, although neither of the latter two actually experienced flooding as the result of the 25 April break-up. This institutional and bureaucratic perspective is science based but highly political. Many authors have described the uneasy relationship between the First Nations of Canada and governments (federal and/or provincial) in the context of resource management (for instance, Notzke 1993, Scott 2001, Howitt 2001, Bone and Anderson 2003, Nadasdy 2003, Berkes et al. 2005). Recently, aboriginal (First Nations, Inuit, Metis) environmental justice issues have been brought to the fore by the June 2007 Aboriginal Day of Action (CBC 2007) and the recent attempt to apologize for and reconcile abuses that occurred within the residential school system (CBC 2008b). As well, recent water quality issues (Escheria coli in October 2005) and flooding (evacuation in April 2006) in the nearby community of Kashechewan have reached the national media (CBC 2006a,b). It is clear from the interviewees that, from a Fort Albany First Nation perspective, the federal and provincial governments' response to the flooding (i.e., a structural approach with limited community involvement) was at least partially motivated by the political implications of ensuring the public safety of First Nations communities.

As a result, in late April of 2008, when the spring break-up caused the waters of the Albany River to rise, an evacuation order was issued when local as well as provincial and federal authorities began to express concern over the potential for a flood. As mentioned previously, some in the Fort Albany community saw this measure as an over-reaction by provincial and federal agencies. Although the community of Fort Albany saw some flooding, Kashechewan was evacuated even though no water ever crested its perimeter dike system.

This more institutional, bureaucratic perspective can also be mapped onto the conceptual model of social learning. It is primarily based on scientific (the science of flood prevention) and, to some extent, governance knowledge (tied to the political interests of the federal government, public perception of its activities, and its fiduciary responsibility to First Nations peoples). With reference to critical reflection, it is difficult to categorize. It can be argued that federal and provincial governments have some sensitivity to aboriginal issues that could be interpreted as an example of triple-loop learning, an apparent reflection on power relations. However, an overreliance on structural approaches to flood damage reduction, an apparent knee-jerk reaction to evacuate and the temporally limited community flood response committee is more likely to represent single-loop learning, and a lack of critical reflection (see lightest-colored region of Fig. 4).

\section{DISCUSSION AND SPECULATION}

\section{Barriers and Bridges to Social Learning and Adaptive Capacity for Flood Damage Reduction in the Fort Albany First Nation}

Many authors point out that intractable conflicts can be perpetuated depending on the way the parties "frame" or define the conflict issues (Schon and Rein 1994, Gray 2003, Bouwen and Taillieu 2004). These different perspectives, as mapped on the SEE systems conceptual model for social learning, represent different definitions of the problem. The first perspective defines the problem of flooding in Fort Albany as a local phenomenon and from a perspective that does not demand a redefinition of the problem but takes it and the resulting "solutions" as the only alternative. This perspective, characterized as indifference to or lack of awareness of the broader causes and consequences of flooding, may be the result of the long history of imposing western bureaucratic structures on aboriginal peoples (Notzke 1993, Howitt 2001, Scott 2001, Bone and Anderson 2003, Nadasdy 2003, Berkes et al. 2005). The second, integrated view of the situation seeks to redefine the problem of flooding and contextualize it in a broad suite of interrelated land-use, cultural, linguistic, and governance issues. The third perspective defines the problem from a government, regulatory perspective. These three non-equivalent frames of reference on the issue of flood damage reduction in Fort Albany do not easily lead to constructive resolutions. We speculate that the identification and description of these three frames or perspectives on the issue of flood damage reduction in Fort Albany help to articulate the 
complex "knowledge landscape" surrounding this issue and allow for more productive discourse on flood response. We also speculate that understanding and articulating the various perspectives in this context may also result in the emergence of alternative and potentially innovative options that may be more beneficial to the community and reduce external resources required to address inevitable future flood events. These potentially positive outcomes rest entirely upon the willingness of all involved in flood damage reduction to come together through collaborative processes.

Fort Albany flood coordination staff described a recent initiative led by the Mushkegowuk Council in conjunction with Emergency Measures Ontario that is intended to take a more integrated approach to emergency measures planning. Instead of simply hiring flood coordination staff mere weeks before spring break-up, this new program would provide funding for a full-time emergency measures coordinator who would be charged with planning for flood and other emergencies, such as fire or epidemics. These coordinators would work collaboratively with staff from Emergency Measures Ontario, Mushkegowuk Council staff, and the other emergency measures coordinators from the other coastal communities. We speculate that this could more effectively integrate the two perspectives described above, the integrative and the bureaucratic. This integration, which would require longer-term, more collaborative processes, would result in a richer, more culturallyappropriate, as well as politically acceptable approach to flood damage reduction.

As for the first perspective, characterized as apathetic, a broad-based program of capacity enhancement for environmental assessment has been undertaken in Fort Albany at the request of the Chief and Council in response to the development of Ontario's first diamond mine within the Mushkegowuk Territory. A similar program of capacity enhancement for flood damage reduction and emergency measures planning could be undertaken in collaboration with the new emergency measures coordinator to enable members of the Fort Albany community to reflect critically on their role in planning for and addressing emergencies in their community and beyond. We speculate that an effective program of capacity enhancement would allow Fort Albany First Nation community members to better understand the options, opportunities, and costs of addressing flood events for their community and to become more effectively involved in the decision-making process.

Understanding the differences among these three perspectives that have emerged through the application of the SEE model highlights the need for stakeholders to reflect critically on their perspectives (i.e., the epistemological context, knowledge types used, and the scale of the perspective, agent, or various levels of social structures). We speculate that clarifying the differences among these perspectives will allow stakeholders to communicate better across perspectives, acknowledge past and current power differentials, and seek novel, innovative opportunities to integrate perspectives and increase adaptive capacity (Armitage 2005).

\section{CONCLUSIONS}

This paper presents a conceptual tool, or heuristic, for describing the epistemological context for social learning. The tool was originally developed in the context of an environmental land-use planning process in southern Ontario, Canada (McCarthy 2009) and has subsequently been applied to the case of flood damage reduction in the remote, First Nations community of Fort Albany in northern Ontario, Canada. This research, and the resulting heuristic, integrates several definitions of social learning that emphasize the importance of critical reflection (Keen et al. 2005, Wals 2007) and its collaborative nature (Pahl-Wostl et al. 2008) and that it is rooted in, and oriented toward, practice through social interactions (Reed et al. 2010).

Our case study of flood damage response in the Fort Albany First Nation provided clear descriptions of the multiple frames or perspectives of the various stakeholders. The heuristic was useful for identifying and conceptually mapping different perspectives based on types of learning described along three axes: a loose typology of knowledge; different levels of critical reflection; and scale. In this way, the heuristic was useful in delineating different perspectives in a given problem context and the associated rationale for particular potential approaches to resolving it. As such, the tool can be used to diagnose conflict within a problem context 
and identify barriers and bridges to resolving differences in perspective by describing each epistemological context. We speculate that our results could form the basis and starting point for future integrative and collaborative flood damage reduction initiatives. Further research could involve exploring the utility of this heuristic as part of a decision-making process to identify and resolve differences in perspective.

Responses to this article can be read online at: http://www.ecologyandsociety.org/voll6/iss3/art18/ responses/

\section{Acknowledgments:}

We would like to thank all interviewees, workshop participants, the Fort Albany First Nation, the Social Sciences and Humanities Research Council of Canada, and the Waterloo Institute for Social Innovation and Resilience (WISIR), SiG at Waterloo and the J.W. McConnell Foundation for support.

\section{LITERATURE CITED}

Argyris, C. 1993. Knowledge for action: a guide to overcoming barriers to organizational change. Jossey-Bass Publishers, San Francisco, California, USA.

Armitage, D. 2005. Adaptive capacity and community-based natural resource management. Environmental Management 35(6):703-715. http:// dx.doi.org/10.1007/s00267-004-0076-z

Bandura, A. 1971. Social learning theory: motivational trends in society. General Learning Press, Morristown, New York, USA.

1986. Social foundations of thoughts and action: a social cognitive theory. Prentice Hall, Englewood Cliffs, New Jersey, USA.

- 1991. Social cognitive theory of moral thought and action. Pages 45-103 in W. M. Kurtines and J. L. Gewirtz. Handbook of moral behavior and development, volume theory. Erlbaum Associates Publishers, Hillsdale, New Jersey, USA.
Berkes, F., and C. Folke. 1998. Linking social and ecological systems: management practices and social mechanisms for building resilience. Cambridge University Press, Cambridge, UK.

Berkes, F., and C. Folke. 2003. Navigating socialecological systems: building resilience for complexity and change. Cambridge University Press, New York, New York, USA.

Berkes, F., R. Huebert, H. Fast, M. Manseau, and A. Diduck. 2005. Breaking ice: renewable resource and ocean management in the Canadian North. University of Calgary Press, Calgary, Alberta, Canada.

Bone, R. M., and R. B. Anderson. 2003. Natural resources and Aboriginal people in Canada: readings, cases and commentary. Captus Press, Concord, Ontario, Canada.

Bouwen, R., and T. Taillieu. 2004. Multi-party collaboration as social learning for interdependence: developing relational knowing for sustainable natural resource management. Journal of Community and Applied Social Psychology 14:137153. http://dx.doi.org/10.1002/casp.777

Canadian Broadcasting Corporation. 2006a. Flooding forces 750 from Kashechewan reserve. [online] URL: http://www.cbc.ca/canada/story/200 6/04/23/kashechewan060423.html

Canadian Broadcasting Corporation. $2006 b$. Kashechewan: water crisis in northern Ontario. [online] URL: http://www.cbc.ca/news/background/ aboriginals/kashechewan.html

Canadian Broadcasting Corporation. 2007. Rail traffic resumes after aboriginal day of protest. [online] URL: http://www.cbc.ca/canada/story/200 7/06/30/rail-blockade.html.

Canadian Broadcasting Corporation. 2008a. Flood forces 2 nd day of evacuations in northern Ontario. [online] URL: http://www.cbc.ca/canada/story/200 8/04/27/ont-flooding.html

Canadian Broadcasting Corporation. 2008b. Northerners await historic residential school apology. [online] URL: http://www.cbc.ca/canada/ north/story/2008/06/11/north-apology.html 
Flood, R. L., and N. R. A. Romm. 1996. Diversity management: triple loop learning. Wiley, Toronto, Ontario, Canada. http://dx.doi.org/10.1108/036849 29610149747

Flyvbjerg, B. 2001. Making social science matter: why social inquiry fails and how it can succeed again. Cambridge University Press, New York, New York, USA.

Fort Albany First Nation Flood Watch. 2006. Fort Albany First Nation flood Watch 2006: spring break-up dates since 1903-2005. Report. Fort Albany First Nation, Ontario, Canada.

Giampietro, M. 2003. Multi-scale integrated analysis of agroecosystems. CRC Press, Boca Raton, Florida, USA. http://dx.doi.org/10.1201/978 $\underline{0203503607}$

Gibbs, G. R. 2002. Qualitative data analysis: explorations with NVivo. Open University Press, Philadelphia, Pennsylvania, USA.

Giddens, A. 1984. The constitution of society : outline of the theory of structuration. University of California Press, Berkeley, California, USA.

Glaser B. G., and A. Strauss. 1967. The discovery of grounded theory: strategies for qualitative research. Aldine de Gruyther, Chicago, Illinois, USA.

Government of Ontario. 2001. Oak Ridges moraine conservation act. Ontario Ministry of Municipal Affairs, Toronto, Ontario, Canada.

Government of Ontario. 2002. Oak Ridges moraine conservation plan. Ontario Ministry of Municipal Affairs, Toronto, Ontario, Canada.

Gray, B. 2003. Framing of environmental disputes. Pages 11-34 in R. Lewicki, B. Gray, and M. Elliot. Making sense of environmental conflicts: concepts and cases. Island Press, Washington, D.C., USA.

Gunderson, L., and C. S. Holling. 2002. Panarchy: understanding transformations in human and natural systems. Island Press, Washington, D.C., USA.
Gunderson, L. H., C. S. Holling, and S. S. Light. 1995. Barriers and bridges to the renewal of ecosystem and institutions. Columbia University Press, New York, New York, USA.

Harries, K. 2008. Crees flown out as Albany river rises. Indian Country Today. [online] URL: http:// www.indiancountrytoday.com/archive/28413599.html

Howitt, R. 2001. Rethinking resource management: justice, sustainability and indigenous peoples. Routledge, New York, New York, USA.

Huntington, H. P. 1998. Observations on the utility of the semi-directive interview for documenting traditional ecological knowledge. Arctic 51:237242.

Jackson, M. C. 2000. Systems approaches to management. Kluwer Academic / Plenum Publishers, New York, New York, USA. http://dx.d oi.org/10.1108/03055720710838470

Kay, J. J., H. Regier, M. Boyle, and G. R. Francis. 1999. An ecosystem approach for sustainability: addressing the challenge of complexity. Futures 31 (7):721-742. http://dx.doi.org/10.1016/S0016-3287 (99)00029-4

Keen, M., V. A. Brown, and R. Dyball. 2005. Social learning in environmental management: towards a sustainable future. EarthScan, London, UK.

Latham Group Inc. 1989. Fort Albany settlement flood control study. Latham Group Inc., Richmond Hill, Ontario, Canada.

Lytwyn, V. P. 2002. Muskekowuck Athinuwick. Original people of the great swampy land. University of Manitoba Press, Winnipeg, Manitoba, Canada.

McCarthy, D. 2009. A critical systems approach to socio-ecological systems: implications for social learning and governance. VDM Verlag, Saarbrücken, Germany.

Mezirow, J. 1998. On critical reflection. Adult Education Quarterly 48(3):185-198. http://dx.doi.o $\mathrm{rg} / 10.1177 / 074171369804800305$ 
Midgley, G. 2000. Systemic intervention: philosophy, methodology, and practice. Kluwer Academic / Plenum Publishers, New York, New York, USA.

Miles, M. B., and A. M. Huberman. 1994. Qualitative data analysis. Second edition. Sage Publications, Thousand Oaks, California, USA. htt p://dx.doi.org/10.2307/2392365

Nadasdy, P. 2003. Hunters and bureaucrats: power, knowledge and Aboriginal-State relations in the southwest Yukon. University of British Columbia Press, Vancouver, British Columbia, Canada.

Nadasdy, P. 2007. Adaptive Co-Management and the Gospel of Resilience. Pages 208-227 in D. Armitage, F. Berkes and N. Doubleday. Adaptive co-management: collaboration, learning, and multi-level governance. University of British Columbia Press, Toronto, Ontario, Canada.

Notzke, C. 1993. Aboriginal peoples and natural resources in Canada. Captus Press, Concord, Ontario, Canada.

O’Donoghue, T., and K. Punch. 2003. Qualitative educational research in action: doing and reflecting. Routledge, New York, New York, USA.

Pahl-Wostl, C., E. Mostert, and D. Tàbara. 2008. The growing importance of social learning in water resources management and sustainability science. Ecology and Society 13(1): 24. [online] URL: http: //www.ecologyandsociety.org/vol13/iss1/art24

Reed, M. S., A. C. Evely, G. Cundill, I. Fazey, J. Glass, A. Laing, J. Newig, B. Parrish, C. Prell, C. Raymond, and L. C. Stringer. 2010. What is social learning? Ecology and Society 15(4): r1. [online] URL: http://www.ecologyandsociety.org/vol15/iss4/ $\underline{\text { resp1/ }}$

Robson, C. 1993. Real world research: a resource for social scientists and practitioner researchers. Blackwell, Cambridge, Massachusetts, USA.

Schon, D. A., and M. Rein. 1994. Frame reflection: toward the resolution of intractable policy controversies. Basic Books, New York, New York, USA.
Scott, C. H. 2001. Aboriginal autonomy and development in northern Quebec and Labrador. University of British Columbia Press, Vancouver, British Columbia, Canada.

Trochim, W. M. K. 2005. Research methods: the concise knowledge base. Atomic Dog, Cincinnati, Ohio, USA.

Tsuji, L. J. S., and E. Ho. 2002. Traditional environmental knowledge and western science: in search of common ground. Canadian Journal of Native Studies 22:327-360.

Tsuji, L. J. S., and E. Nieboer. 1999. A question of sustainability in Cree harvesting practices: the seasons, technological and cultural changes in the western James Bay region of northern Ontario, Canada. Canadian Journal of Native Studies 19:169-192.

Walker, B., S. Carpenter, J. Anderies, N. Abel, G. S. Cumming, M. Janssen, L. Lebel, J. Norber, G. D. Peterson, and R. Pritchard. 2002. Resilience management in social-ecological systems: a working hypothesis for a participatory approach. Conservation Ecology 6(1): 14. [online] URL: http ://www.consecol.org/vol6/iss 1/art14

Walker, B., and D. Salt. 2006. Resilience thinking: sustaining ecosystems and people in a changing world. Island Press, Washington D.C., USA.

Waltner-Toews, D., J. J. Kay, T. Murray, and R. C Neudoerffer. 2004. Adaptive methodology for ecosystem sustainability and health (AMESH): an introduction. Pages 317-349 in G. Midgley and A. E. Ochoa-Arias, editors. Community operational research: systems thinking for community development. Plenum Publications/Kluwer Press, New York, New York, USA.

Wals, A. E. 2007. Social learning: towards a sustainable world. Wageningen Academic Publishers, Wageningen, The Netherlands.

Webler, T., H. Kastenholz, and O. Renn. 1995. Public participation in impact assessment: a social learning perspective. Environmental Impact Assessment Review 15(5):443-463. http://dx.doi.or $\mathrm{g} / 10.1016 / 0195-9255(95) 00043-\mathrm{E}$ 
Whitelaw, G. S. 2005. The role of environmental movement organizations in land use planning: case studies of the Niagara Escarpment and Oak Ridges Moraine processes. Dissertation, University of Waterloo, Waterloo, Ontario, Canada.

Whitelaw, G., and D. McCarthy. 2008. Governance, social capital and social learning: insights from activities in the Long Point World Biosphere Reserve and Oak Ridges Moraine, Ontario, Canada. Pages 123-130 in O. Opermanis and G. S. Whitelaw, editors. Economic, social and cultural aspects in biodiversity conservation. Press of the University of Latvia, Baznicas, Latvia.

Wynne, B. 1992. Misunderstood misunderstanding: social identities and public uptake of science. Public Understanding of Science 1(3):281-304. http://dx.d oi.org/10.1017/CBO9780511563737.002 